\title{
Study on Construction of Innovation Culture System in Collaborative Innovation Center
}

\author{
Sun Qingzhong, Huang Fangfang*
}

Jinan University, Guangzhou, Guangdong,China

Keywords: Collaborative Innovation Center; Innovation Culture

\begin{abstract}
Implementation of "2011 project" is another major strategic plan for China's higher education front to reflect the national will, following the "211 Project" and "985 Project". "To create a cultural environment conducive to collaborative innovation" is an important part of the reform of its mechanism. In this paper, by clarifying the basic connotation of "innovative culture", combined with the domestic and international innovation culture environment and its development trend currently, we put forward the guiding ideology of the construction of "innovative culture" system, and focus on the specific content of its construction.
\end{abstract}

\section{Introduction}

Innovative culture is the cultural connotation of value, attitude, belief and so on, including innovation concept culture and innovation system culture. Concept culture is the most important thing that affects innovation activities. The basic ideas contained in concept culture, including faith, reason, value and so on, determines whether people's activities can be "innovative". System culture refers to the rules and order system of innovation, which reflects the values, ethics, customs and other cultural factors.

Collaborative innovation is a complicated systematic project. In order to really allow the innovative elements of different pursuit, background and identities to form a powerful force, first of all, first of all, we need to establish a cultural value foundation which can be agreed by every innovation subject. If the convened units or individuals lack the necessary mechanisms to integrate cultural values, it may be less effective. Culture can drive the realization of collaborative innovation in two aspects. On the one hand, culture is a banner, an image display, and also an inspiring spiritual strength; on the other hand, outstanding culture can enrich people's spiritual world, and enrich people's knowledge and ideas, making people full of emotion and full of ideals. Cultural influence is often reflected in concrete action, that is, on the practical level. Innovation culture is to use the unique cohesion and inspiring force in the cultural elements to inspire people, and then motivate people to act and to continuously achieve innovation.

\section{Environment Analysis and New Trend of Innovation Culture}

In recent years, with the increasing emphasis on innovation in our country, innovative cultural construction has made a lot of achievements, such as proposal of innovative cultural strategy, initial formation of innovation mechanism and construction of innovation platform, etc. However, the establishment of collaborative innovation center has just begun, and there are still some problems to be solved in the construction of innovation culture, so we should pay enough attention to it.

1. The outdated traditional concept of innovation has great restriction to the development of innovative culture. Due to the influence of negative factors in traditional culture and speed preference in scientific research, the utilitarian research concept should not be overlooked. In addition, in teaching activities, there are also the phenomenon of academic politicization, economization and incentive mechanism of utilitarianism. Academic misconduct appears from time to time, so innovation is unsustainable.

2. The rigid and conservative mechanism is of large bound to innovation culture. From the international perspective, Nordic countries' innovation competitiveness greatly exceeds the United Kingdom, France and other Western European countries. One of the most important reasons is that 
the business parks and innovation alliance organization in these countries attaches great importance to the construction of innovative mechanisms, and pay close attention to each other's culture. A good mechanism of innovation culture greatly promotes the effect of innovation, becoming the power source of innovation development. From the perspective of China's environment, Due to the long-term mechanism rigid, it lacks of Innovative cultural potential.

3. Utilitarian traditional environment produces a big obstacle to innovation and cultural advancement. Due to the lack of innovation value, we often have misunderstanding on status and role of innovation. In the researchers' team, the pursuit of truth has not become an inner professional concept, and questioning and criticism has not become deep psychological character; in research activities, lack of faith and courage to achieve world-class technology innovation and integration; on the level of public opinion, lack of relatively liberal academic space, and the sustainable development of innovative ecological environment has not been established.

Currently, the development of innovation culture is never limited to a certain region or country, and a professional or subject, neither. If place the collaborative innovation of innovation culture center in complex and diverse international environment, we can clearly see the new trend of innovation culture development:

1. Normality. Innovation without culture can only be passive water. Similarly, culture without innovation cannot make any progress. From science to the humanities, from the brand LOGO design to product development, from "Silicon Valley culture" to the "Nordic Innovation", it more and more embodies the culture of innovation. It can be said that, in the initial stage of collaborative innovation center, if we do not introduce the concept of innovation culture, it not only directly affect the effectiveness of collaborative innovation center, but also it will ultimately affect the long-term presence of the center.

2. Internationalism. At present, with increasingly advancing of internationalization and information technology, innovation culture is increasingly penetrated into every corner of the world. Both developed and developing countries all need to actively promote innovation and international strategy. University of Cambridge, the German Society of $\mathrm{Ma} \mathrm{Pu}$, French Research Center and other international famous universities and research institutions have formed unique innovation international development strategies. Implementation of innovation internationalization strategy can not only make use of both domestic and foreign resources for collaborative innovation, but also reflect the international status of national scientific research institutions.

3. Openness. Nowadays, scientific research only relying on internal resources to carry out the high cost of innovation has not been possible to deal with the growing pressure from the industry, business, consumers and other groups. Under this background, "Open innovation" has become the dominant mode of innovation culture. Lead units of collaborative innovation center are universities, but its participating units may be governments, businesses, and trade associations, etc. with the theory of open innovation in enterprises, we believe that innovation culture also requires open innovation, which emphasizes playing the advantages of the synergy units, and finally resolve the "innovation dilemma" in universities. In fact, Implementation of the "2011 Project" is to break the "ivory tower" type of research in universities. By breaking through barriers among innovation subjects, fully release the innovation elements vitality of talent, capital, information, technology and so on, to mobilize the enthusiasm and creativity of wide range of innovative body enterprises, and implement deep cooperation and open innovation.

\section{The Guiding Ideology in the Construction of "Innovation Culture" System}

Around the overall objective to create a cultural environment conducive to collaborative innovation, focus on building an academic atmosphere of freedom and openness, encouraging innovation and tolerance, and advocate the spiritual fashion of hard work, dedication, pragmatic, unity and cooperation. Establish the linkage system between university, government, industry and enterprise, and effectively strengthen the construction of innovation culture, to lay a solid foundation for promoting the innovation ability of the university. Under this guidance, to complete the construction of innovation cultural system, we need to adhere to three principles: 
Adhere to the principle of "inheritance and development, experience and innovation". Not only based on national conditions to Inherit and carry forward the cultural essence of our heritage, but also transcend the negative influence of traditional culture. In particular, be born to learn from the essence of advanced culture at home and abroad, and gradually the innovation culture system with its own characteristics.

Adhere to the principle of "people oriented". In the construction of innovation culture system, we should pay close attention to the needs and development of people, and give full play to their enthusiasm, initiative and creativity. Establish and improve the scientific decision-making and evaluation mechanisms, earnestly to cultivate the cultural consciousness, so that allow them to enjoy the fruits of innovation culture construction. Meanwhile, promote team spirit of innovation, to enhance the overall innovation capability.

Adhere to the principle of four combinations. First is combination of practice and planning, that is, to improve and perfect the innovation system in practice; second is combination of short-term and long-term, gradually and continuously enhancing the culture; third is combination of innovation culture construction and management, so that management practices fully reflect the rich cultural connotations; forth is combination of individual and team, to make the innovation culture construction to play the individual initiative and team work as well.

\section{Construction of "Innovation Culture" System in Collaborative Innovation Center}

\section{Build "innovative culture platform".}

First, build innovative cultural communication platform. Through the construction of cultural, scientific integration platform and related sub-platform, Accelerate the construction of scientific research achievement transformation service system, and strengthen the integrated development of science and technology and innovation culture, to enhance service capability and aggregate the new culture in line with center development direction. Make efforts to hatch and spawned a number of research projects of high creative level, high technical content and large market potential, so that foster a new economic growth point of innovation culture. Meanwhile, with the help of the construction of creative products, creative design, innovation competition and other platforms, improve the innovation culture environment, and serve the scientific research innovation with innovative culture.

Second, build innovative culture technology platform. In the Internet Era, The rapid development of information technology has provided an endless space and a variety of means for the dissemination of innovation culture. Center staff can create a new world of culture through the network of new communication channels, and interpret the values of efficiency, democracy, equality, smooth and pleasure, etc. therefore, from the perspective of technology, we should strengthen cultural and technological development, including mobile culture, Internet culture, fashion design, animation design, digital TV, etc. Making full use of the latest technology, to build a solid ellipse innovative technology platform, thus build a comprehensive and modern innovative cultural atmosphere.

Third, Build innovative culture propaganda platform. Strengthen the idea of "innovation first" throughout the center, establish the column of "innovative cultural dynamics", and timely report the research culture dynamics of the center, domestic and foreign. Strengthen the construction of central letters, television advertising screen and network propaganda column, to build a multi-dimensional propaganda platform, so that expand coverage and influence of propaganda.

\section{Promote the Transformation of Innovative Cultural Mechanism.}

Firstly, individual generation mechanism of innovation cultural spirit. It clearly put forward in Higher Education Law: higher education should cultivate the people of innovative spirit. The formation of innovative culture depends on the individual's creative desire and consciousness. Therefore, in creating collaborative innovation center, to establish the individual generation mechanism of innovation cultural spirit, we must encourage the individual, team, platform and sub center initiative spirit, and set up an innovative cultural mechanism. On the one hand, strengthen the 
cultivation of innovative thinking. Innovative thinking cultivation is the key to construct the whole innovation activity, and the core of innovation as well. On the other hand, we must coordinate the cultivation of creative emotion and creative thinking together. The process of innovation is not just a purely intellectual activity, but also needs to take the creative emotion as the driving force, and take the good personality quality as the backing. Creative emotion refers to the motive of creation, interest to explorer, strict attitude, indomitable will and other emotional factors, which should become the starting point of creativity cultivation and development.

Secondly, incentive mechanism of Innovative culture. First of all, should break the equalitarianism of salary and reward, and set up a distribution system based on innovation performance, to form an allocation mechanism to innovation, which can better reflect the principle of "income contribution" and mobilize the initiative and creativity of the staff in the center. Then, should respect for the personality, opinions, personal interests and development needs of the center member, and create good career development opportunities for them.

Thirdly, generation mechanism of innovative culture. Innovative culture is the genetic code of collaborative innovation. Creation of Central innovation culture atmosphere

\section{Deepen Innovation Culture Environment Construction.}

First, advocate the pursuit of scientific spirit of truth and rigorous scholarship. Scientific spirit is the primary basis of innovation, so we should set up the values of pursuing the truth and be creative, and encourage academic debate. Promote the organic unity of academic democracy and academic responsibility, and strengthen the construction of academic ethics, strive to create a good academic environment of free and open, harmonious and enterprising. Second, Foster risk-taking, failure tolerant and inclusive spirit. There is a huge risk of failure for technological innovation, especially primitive technological innovation, of which has higher uncertainty and greater risk. Therefore, to encourage innovation, support the exploration, we should allow and tolerant failure. Third, form a policy environment to encourage innovation, so more resources, wisdom and power would be devoted into the innovation activities. It requires collaborative innovation center to further optimize the policy orientation, to make the original innovation value more fully show. in addition, should strengthen intellectual property protection, to effectively protect the rights and interests of innovators, and enhance internal innovation awareness.

\section{References}

[1] Ye J. The Establishment of Innovation Culture System of Architecture Execution Enterprises[J]. Fujian Architecture \& Construction, 2007.

[2] Wang Pingju, Zeng Guoping, Center of Science, et al. Envolution and Structure of Innovation Culture System[J]. Science \& Technology Progress \& Policy, 2015.

[3] Zhang M. Innovation Culture in Development Zones on the Basis of Innovation Theory[J]. Journal of Hebei University of Economics \& Trade, 2009.

[4] Gong P X. On the Construction of Independent Innovation Culture in Our Country[J]. Journal of China Executive Leadership Academy Jinggangshan, 2010.

[5] Zhang H G, Wang Y J. On Constructing Innovation Culture in Modern Universities[J]. Journal of Nanjing University of Aeronautics \& Astronautics, 2009.

[6] Zhao D, Qian F. Effect of Regional Culture in Regional Innovation System - A Case Comparison between Silicon Valley and Tsukuba[C]// Proceedings of the 2008 International Conference on Information Management, Innovation Management and Industrial Engineering Volume 01IEEE Computer Society, 2008:258-262.

[7] Zhang M, Ma H. Discussing Innovative Culture in Colleges[J]. Science Education Article Collects, 2011. 
[8] Han J. Research on Innovative Culture of Agricultural Research Institutes[J]. Journal of Anhui Agricultural Sciences, 2011. 